\title{
La prostitución: notas para el debate
}

\author{
Prostitution: notes for debate
}

\author{
PABLO DE LORA* \\ Facultad de Derecho (UAM) \\ ORCID ID: 0000-0001-6992-0559
}

doi: https://doi.org/10.20318/labos.2020.5542

Resumen: Estas notas tienen la única pretensión de mostrar qué argumentos pueden ser esgrimidos frente a la posibilidad de intercambiar sexo por dinero si asumimos una concepción desacralizada o no significativa del sexo de acuerdo con la cual el consentimiento de los intervinientes es condición necesaria y suficiente de la licitud moral y jurídica de la relación sexual. A lo largo de estas páginas se analizan los argumentos basados en alguna forma de perfeccionismo moral, la falta de consentimiento, el daño, la instrumentalización y el conocido como argumento expresivo.

Palabras clave: sexo, prostitución, daño, perfeccionismo, paternalismo, consentimiento, instrumentalización, industria del sexo.

Abstract: $\quad$ In the following pages I attempt to show what arguments may be raised against the exchange of sex for money. The difficulty for those who argue against prostitution lies in the fact that we hold a non-significant conception of sex according to which consent is a necessary and sufficient condition for the moral and legal acceptance of sexual relations. I analyze 5 arguments: moral perfectionism, the lack of consent that allegedly implies buying sex, harm, instrumentalization and the so-called "expressive arguments".

Keywords: sex, prostitution, harm, perfectionism, paternalism, consent, instrumentalization, sex industry.

\section{Introducción}

Imaginen dos individuos. Se miran cruzando un paso de cebra. Se atraen. Se citan con gestos inapelables. Se dirigen a un lugar reservado. Se besan, se abrazan y tienen lo que comúnmente describimos como "relaciones sexuales". Tal vez sin mediar palabra alguna. ¿¿Fueron buenas las razones para hacerlo? A quienes tienen en su utillaje normativo la autonomía personal como herramienta más importante, la pregunta les sonara improcedente, excéntrica. ¿Cómo que "buenas razones"? Su perplejidad derivará seguramente del hecho de que consideran que tales razones son "relativas al agente", es decir,

*pablo.delora@uam.es 


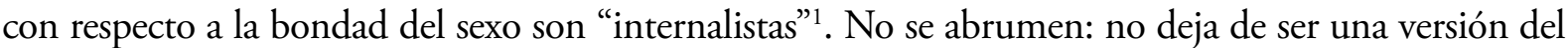
"con su pan se lo coman" (con perdón). Siendo internalistas todo lo que les importará saber para enjuiciar a los protagonistas del escarceo es si desearon hacer lo que hicieron, si no fueron forzados, si no se aprovecharon de la eventual menor edad o situación de embriaguez del otro ${ }^{2}$. Imaginen ahora la misma escena pero con un final, tal vez, menos feliz. Uno de los individuos le dice al otro: "son 50 euros". ¿ No deberíamos mantener nuestro anterior enjuiciamiento aunque descubramos ahora que la razón por la que una de las partes accedió a mantener relaciones sexuales fue el dinero? ¿Qué resta moralmente el dinero si mantenemos constante la autonomía de quienes se relacionan sexualmente? Y más importante aún: ¿Cómo resistirse a esta conclusión que haría de la prostitución algo necesariamente permisible desde el punto de vista jurídico, toda vez que aceptamos la permisibilidad jurídica de las relaciones sexuales frívolas, casuales, por cualquier razón siempre que sean consentidas? ${ }^{3}$ Las notas que siguen son meramente un intento de cartografiar las razones que pudiéramos albergar para ejercer esa resistencia.

\section{Perfeccionismo moral}

Las avenidas para ello son diversas. La primera de ellas consiste en negar la mayor, sostener que sí hay buenas o malas razones para tener relaciones sexuales que van más allá de lo que las partes deseen. En suma, rechazar el internalismo y abrazar el "externalismo". El lector seguramente podrá alcanzar esas razones en el almanaque de su memoria, tal vez de sus propias convicciones: tener hijos, estar enamorado... Sin duda no a cambio de dinero que corrompe el significado profundo y genuino del sexo; una práctica que constituye, esencialmente, una actividad de recíproca dación de placer, nunca un "negocio" 4 . Y en esto encuentra uno curiosos compañeros de navegación. Si pensamos en España, tanto el anarquismo de los años 30 del pasado siglo, el de la asociación Mujeres Libres que promovía los "liberatorios" de prostitución5, cuanto la Iglesia Católica a través de la Junta Nacional de Protección a la Mujer, pasando por el insigne penalista Luis Jimenez de Asúa ${ }^{6}$, o, más recientemente, el filósofo conservador británico Roger Scruton ${ }^{7}$, todos ellos comparten la idea de que la prostitución es "indecente", aunque el arqueo de las causas diverja: la posmodernidad que siguió a los polvos (ejem) de Mayo del 68; el sistema de explotación capitalista; renegar de la fe; la orfandad, o, al fin, la falta de formación hogareña al decir de ilustres representantes del nacional-catolicismo español ${ }^{8}$.

En sociedades liberales y plurales como las nuestras en las que razonablemente discrepamos sobre la vida buena, esas razones no son asequibles, pertenecen al dominio de la convicción íntima o privada, es decir, no pueden esgrimirse en el foro público como justificaciones de normas jurídicas que prohíben acciones o actividades con carácter general. Imaginen que adoptamos la versión de la bondad del sexo que se propala en algunos pagos feministas de nuestros días: el placer mutuo, la empatía ${ }^{9}$ ¿Qué hacemos con las prácticas masturbatorias no mutuas, el sadomasoquismo, las palabras gruesas al oído o las muchas parafilias que son abyectas a los ojos de muchos? ¿Las prohibimos también por las mismas razones que habríamos de prohibir el intercambio de sexo por dinero?

\footnotetext{
${ }^{1}$ Alan H. Goldman (1977): "Plain Sex", Philosophy and Public Affairs, Vol. 6, n³, primavera 1977, pp. 267-287.

${ }^{2}$ Se trata de conductas todas ellas no sólo moralmente reprochables sino también penalmente típicas.

${ }^{3}$ Ole Martin Moen “Is Prostitution Harmful?", The Journal of Medical Ethics, Vol. 40, 2014, pp. 73-81.

${ }^{4}$ Sascha Settegast, "Prostitution and the Good of Sex", Social Theory and Practice, Vol. 44, n³, July 2018, pp. 377-403, p. 398.

${ }^{5}$ Una suerte de cotolengos en los que dar a las prostitutas tratamiento psiquiátrico, educación moral y oportunidades laborales; véase la descripción y objetivos en el número 5 de la revista Mujeres libres (1936) de la CNT (disponible en: https://cgt.org.es/wpcontent/uploads/2017/10/Mujeres-Libres-05.pdf).

${ }^{6}$ Libertad de amar y derecho a morir, Historia Nueva, Madrid. 1928.

${ }^{7}$ Sexual Desire. A Philosophical Investigation, Bloomsbury, 1986.

${ }^{8}$ Ernesto Jiménez Asenjo, Abolicionismo y prostitución, Reus, Madrid, 1963, pp. 150-151.

${ }^{9}$ Settegast, op. cit.
} 


\section{Falta de consentimiento}

Cabría, en segundo lugar, sostener que cuando media el dinero la relación sexual no es consentida, que toda forma de prostitución es, en el fondo, una violación pues la libre elección de quien se prostituye es un "mito"10. Esta avenida resulta poco prometedora. Preguntémonos, en primer término, por la naturaleza de tal tesis. Si se trata de una definición estipulativa de la prostitución, como tal no prueba nada, y enarbolada como un argumento concluyente más bien incurre en una flagrante petición de principio. El razonamiento discurriría así: "toda relación sexual a cambio de dinero es una forma de violencia; la prostitución es una relación sexual a cambio de dinero, luego la prostitución es una forma de violencia”. La conclusión se sigue lógicamente delas premisas, pero, ¿por qué resultaría siempre una forma de violencia el intercambio de sexo por dinero? Para los miembros de la tribu Merina, que habita en Madagascar, es un signo de respeto que el marido pague a la mujer por tener relaciones sexuales ${ }^{11}$. Y en nuestro contexto socio-cultural: ¿̨no podrían ser algunos arreglos matrimoniales especies de ese género como sostuvo célebremente Simone de Beauvoir en El segundo sexo $^{12}$ o Marx y Engels el Manifiesto Comunista? Si los matrimonios o la vida en pareja son formas de violencia, ¿cómo es que las permitimos?

Es indudable que puede haber circunstancias en las que ese consentimiento de quienes ejercen la prostitución está viciado o no puede ser considerado como genuino. Pensemos en la extrema necesidad de una de las partes que accede a la prestación sexual porque sus alternativas para la satisfacción de otras necesidades básicas son inexistentes. Pero, ¿es así en todos los casos? La respuesta, a la luz de lo que las propias prostitutas señalan y de lo que sabemos, es negativa ${ }^{13}$. ¿Por qué habría de ser distinto el intercambio de sexo por dinero de otros intercambios que involucran actividades muy penosas o arriesgadas que se desarrollan de ordinario? Los médicos hacen tactos rectales o aclaran secreciones a pacientes; los microbiólogos analizan esputos y heces, los masajistas y fisioterapeutas se las ven con cuerpos deformes, los actores porno repiten escenas que pueden resultar humillantes, los fontaneros desatrancan retretes colmatados, los bomberos alcantarillas y los militares se entrenan para ser carne de cañón.

Quienes transitan esta avenida, además, no se la creen en el fondo pues si de verdad pensaran que toda relación sexual mantenida por dinero es una violación no reclamarían meramente la adopción del modelo "nórdico" para combatir la prostitución ${ }^{14}$, sino que exigirían que a los clientes se les imputaran esos delitos contra la libertad sexual sin necesidad de recurrir a figuras específicas o a embarcarse en largos y estériles debates sobre el alcance de la "tercería locativa".

\section{El argumento del daño}

Pero, quienes acceden a tener relaciones sexuales a cambio de dinero ¿acaso no incurren en daños ciertos que eventualmente justifican el paternalismo del poder público sobre dichas actividades? Son evidentes los perjuicios generados por la prostitución vinculados a la transmisión de enferme-

\footnotetext{
${ }^{10}$ Ana de Miguel, Neoliberalismo sexual. El mito de la libre elección, Cátedra, Madrid, 2015.

${ }^{11}$ Jason Brennan y Peter M. Jaworski, Markets. Without Limits. Moral Virtues and Commercial Interests, Routledge, New York-London, 2016, p. 65.

${ }^{12}$ El segundo sexo, Cátedra, Madrid (traducción de Alicia Martorell), 2001 (1949), p. 356.

${ }^{13}$ La investigación de Marina Llobet al respecto de la falta de rigor de las cifras frecuentemente divulgadas sobre la incidencia de la trata en España es concluyente; véase “PProstitución?: ni sí ni no, sino todo lo contrario. Sesgos empíricos, contradicciones de lege lata y desaciertos de lege ferenda”, Revista Electrónica de Ciencia Penal y Criminología, 19-19, 2017.

${ }^{14}$ Suecia fue pionera en instaurar un modelo prohibicionista que castiga solo al cliente. Después han seguido su estela Noruega, Islandia, Irlanda del Norte y Francia.
} 
dades sexuales, la depresión, el insomnio, el estrés, cuando no la violencia incluso con resultado de muerte a manos de los clientes ${ }^{15}$. Claro que también es cierto que: a) muchos de esos daños tienen una fuente "extrínseca" a la práctica en sí pues derivan del estigma social, un estigma que a su vez se ve alimentado precisamente por la prohibición o censura jurídica ${ }^{16}$; b) no todos los supuestos en los que se intercambia sexo por dinero transcurren bajo esas condiciones de peligro, y, en todo caso c) la respuesta del poder público no necesariamente ha de ser la prohibición sino más bien el del establecimiento de un marco regulatorio que minimice o elimine esos riesgos o daños (más sobre esto enseguida).

\section{Instrumentalización}

Cabría, en un modo ligeramente distinto, apelar a que el servicio sexual a cambio de dinero vulnera el imperativo categórico kantiano puesto que implica tratar a quien ofrece el servicio sexual meramente como un instrumento. De nuevo, se trata de un argumento que "probaría demasiado", es decir, obligaría a proscribir o censurar prácticas que entendemos admisibles moral y jurídicamente. Para empezar, bajo una determinada concepción de la actividad sexual, ésta sería siempre una forma de instrumentalización del otro. Así lo entendía el propio Kant en sus Lecciones de Etica donde sostiene que sólo mediante el contrato matrimonial y el compromiso vital íntegro que implica se logra purgar esa esencial degradación del ser humano que acontece al convertirse en medio de la satisfacción sexual ajena ${ }^{17}$.

En realidad no es por mor de la práctica sexual per se -medie o no dinero- por lo que se puede producir una vulneración del imperativo categórico kantiano, sino, de nuevo, por las condiciones de su realización. Y es que no basta con que tratemos a los demás como instrumentos -todos lo hacemos continuamente- sino meramente como tales. Y ello no viene determinado, a mi juicio, porque el desempeño sea descarnadamente fisiológico o corporal (como típicamente se denuncia que ocurre en los supuestos de la prostitución y también en análogos servicios como la gestación por sustitución). Al fin y al cabo, no hay actividad para otros -llámese trabajo desde el punto de vista del Derecho laboral, o prestación de servicios con o sin remuneración- que no involucre todo nuestro "cuerpo": estas líneas que mal escribo ahora mismo, bien que lo haga con mucho gusto, exigen que todo mi metabolismo celular se centre fundamentalmente en estar alerta y concentrado para no desbarrar en exceso.

Evitar esa instrumentalización moralmente odiosa, entender que la prostitución plantea un problema esencialmente "regulatorio", es el espíritu que anida en la apuesta "reglamentista" o "regulacionista", una llamada a la intervención del poder público para que los trabajadores del sexo (también los hombres y las mujeres trans, también otros profesionales del sexo que no ejercen la prostitución) desarrollen su actividad dignamente; quizá, como se discute en las contribuciones que siguen, no estando en ningún caso sometidas al poder de dirección ajeno, ni siendo institucionalmente considerada la prostitución meramente como "un trabajo más" de forma tal que pueda ser ofrecida por los servicios de empleo a quienes demanden trabajo, o engrosando el catálogo de las profesiones u oficios que se aprenden ${ }^{18}$.

\footnotetext{
${ }^{15}$ Para un detalle exhaustivo véase Frej Klem Thomsen, "Prostitution, disability and prohibition", The Journal of Medical Ethics, Vol. 41, 2015, pp. p. 452.

${ }^{16}$ Martin Moen, cit. Si la práctica de relaciones sexuales entre personas del mismo sexo genera depresión porque socialmente los gays y lesbianas son estigmatizados, ¿constituye esa una buena razón para prohibir la práctica?

${ }^{17}$ Immanuel Kant, Lecciones de Ética, Crítica, Barcelona, 1988, p. 207.

${ }^{18}$ Agustí Vicente, "Prostitution and the Ideal State. A Defense of a Policy of Vigilance", Ethical Theory and Moral Practice, publicado en línea el 13 octubre 2015.
} 


\section{El argumento expresivo}

La más prometedora de las avenidas es, a mi juicio, la que muestra que cuando hablamos de la prostitución como un problema ético y por ende jurídico, el argumento del sexo casual -ese razonamiento con el que arrancaba estas páginas y de acuerdo con el cual cualquiera que haya desacralizado la actividad sexual no puede tener nada que objetar al sexo por dinero- ese argumento, digo, no es útil porque la prostitución es mucho más que intercambiar sexo por dinero. La prostitución es problemática qua industria por lo que socialmente "expresa" y consolida, sostiene un sector del feminismo pujante en nuestros días ${ }^{19}$. Dicho de otra forma, "lo malo" de la prostitución es que evidencia la desigualdad lacerante y persistente entre hombres y mujeres, pues en un mundo donde hubiera igualdad de sexos no habría prostitución, es decir, no habría una actividad consistente en que ellos -como colectivo explotador paradigmático- tienen a su disposición la posibilidad mercantil de comprar el placer sexual a ellas, el colectivo explotado paradigmáticamente. Al decir de Jeffrey Gauthier: "La oposición feminista a la prostitución no necesariamente es, y frecuentemente no es, algo dirigido contra la esencia de la práctica, sino más bien hacia la práctica tal y como se conforma en una sociedad gobernada por un trasfondo de asunciones sexistas" 20.

La fuente del "estrés moral" que nos genera la prostitución, y la consiguiente apuesta por su "abolición”, es la existencia de un entramado de reglas e instituciones (de órdenes jurídicos diversos) que "normaliza" -en su más prístino sentido de hacer "normado"- el arrendamiento de un servicio íntimo. Así pues, cualquier forma de "reglamentismo" del ejercicio de la actividad prostitucional no es sino una odiosa manera de apuntalar lo que debe ser simplemente desterrado en aras al ideal de la igualdad.

A mi juicio, el argumento se puede entender de formas distintas que conviene deslindar. Cabe, en primer lugar, interpretarlo como la censura a ciertas formas en las que la industria del comercio sexual pudiera mostrarse: pensemos en el tipo de exhibición que ha hecho célebres a las calles del Barrio Rojo de Amsterdam; imaginemos que ese modelo de "arrendamiento corporal" se extendiera en toda la geografía urbana, con publicidad en los medios, etc. Bien pudieran tener tales "normalizaciones" los efectos deletéreos que denuncian quienes esgrimen el argumento expresivo. Así y todo, lo que no se sigue de ello es que haya que abolir toda forma de prostitución, salvo que regresemos a nuestra casilla de salida perfeccionista bajo el expediente de considerar que mantener relaciones sexuales por dinero nunca es una buena razón y que por ello debe prohibirse jurídicamente. No siendo así, el argumento expresivo alimenta en puridad el regulacionismo o reglamentismo que antes describía someramente.

Alternativamente, cabe entender el argumento expresivo como una apelación a la existencia de una relación de causalidad bidireccional de acuerdo con la cual la prostitución alimenta la desigualdad estructural entre hombres y mujeres, y ésta a su vez aquélla. ¿Cómo concebir entonces la existencia de otras industrias sexuales, marginales en comparación, que no se centran en las relaciones sexuales entre hombres y mujeres o en los deseos sexuales de los hombres con respecto a las mujeres? ¿Qué papel juegan esas otras formas de prostitución? ¿Cómo entender la prostitución gay? ¿Y la demanda de mujeres que pagan a hombres para obtener satisfacción sexual? Es un hecho incontestable cuán abrumadoramente imperante es la prestación de servicios sexuales de mujeres a hombres frente a todas esas otras presentaciones del fenómeno de la prostitución, pero aquél, en su esencia, no difiere: relaciones sexuales, que de otro modo no se tendrían, a cambio de dinero.

\footnotetext{
${ }^{19}$ Por todos, Debra Satz, Por qué algunas cosas no deberían estar en venta: los límites morales del mercado, Siglo XXI, 2015, p. 200.

${ }^{20}$ Jeffrey Gauthier, "Prostitution, Sexual Autonomy and Sex Discrimination", Hypatia, 26, 1, winter 2011, pp. 166-186, p. 174 (cursivas mías).
} 
Es más, está muy lejos de estar contrastado empíricamente -esa es la naturaleza de esta versión del argumento expresivo- que la existencia de la prostitución contribuya a, o sea el reflejo de, la desigualdad de sexos. Estudios recientes no muestran eso sino más bien lo contrario. Así, una encuesta desarrollada en los Estados Unidos entre clientes de servicios sexuales muestra actitudes menos sexistas que las de la población en general ${ }^{21}$.

En definitiva, la prestación de servicios sexuales a cambio de dinero de un modo "profesionalizado" no es una actividad moralmente inocua, $y$, por razones vinculadas al daño potencial de quienes prestan el servicio y en aras a la evitación de estereotipos socialmente perniciosos, el Derecho debe intervenir aun de modo no prohibitivo. El llamado "abolicionismo", en la medida en que pretende imponer una visión sobre la relación sexual "buena" (por igualitaria) y no sólo "correcta" (jurídicamente aceptable por cuanto es consentida) constituye, a mi juicio, una forma de perfeccionismo moral incompatible con el valor de la autonomía de los individuos.

${ }^{21}$ Barbara G. Brents et.. el., "Are Men Who Pay for Sex Sexist? Masculinity and Client Attitudes Toward Gender Role Equality in Different Prostitution Markets", Men and Masculinities, 4 de febrero de 2020 (https://doi.org/10.1177/1097184X20901561) 